\title{
Evaluation of Different Fractions of Garcinia kola Extracts against Multidrug Resistant Clinical Bacterial and Fungal Isolates
}

\author{
Lorina Ineta Badger-Emeka ${ }^{{ }^{*}}$, Hany Ezzat Khali|2,3, Promise Madu Emeka ${ }^{2}$
}

Lorina Ineta Badger-Eme$\mathrm{ka}^{1 *}$, Hany Ezzat Khali| ${ }^{2,3}$, Promise Madu Emeka ${ }^{2}$ 'Department of Biomedical Sciences, College of Medicine, King Faisal University, Al-Ahsa, KINGDOM OF SAUDI ARABIA.

2Department of Pharmaceutical Sciences, College of Clinical Pharmacy, King Faisal University, Al-Ahsa, KINGDOM OF SAUDI ARABIA.

${ }^{3}$ Department of Pharmacognosy, Faculty of Pharmacy, Minia University, Minia 61519, Egypt.

\section{Correspondence:}

\section{Dr. Promise Madu Emeka}

Department of Pharmaceutical Sciences, College of Clinical Pharmacy, King Faisal University, Al-Ahsa, KINGDOM OF SAUDI ARABIA.

Email: pememka@kfu.edu.sa

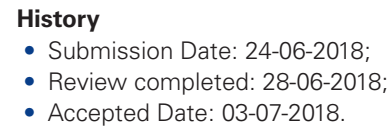

DOI : 10.5530/pj.2018.5.178

Article Available online http://www.phcogj.com/v10/i5

\section{Copyright}

(c) 2018 Phcog.Net. This is an open-access article distributed under the terms

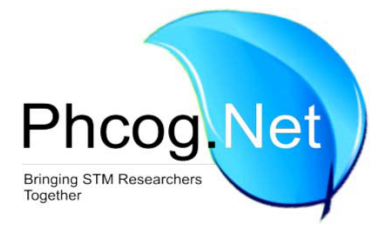

\begin{abstract}
Background: The effectiveness of antibiotics used in the treatment of bacterial infections has been on the decline due to bacterial resistance. To improve clinical management of recalcitrant bacterial infections, alternative therapy such as medicinal plant products are now being evaluated. This study investigates the antimicrobial effects of Garcinia kola fractions on clinical isolates of multidrug resistant gram negative bacteria and Candida. Materials and Methods: Escherichia coli, Klebsiella pnemoniae, Acinetobacter baumannii, Serratia marcescens and Candida species were used for the study. Microbial isolation and antimicrobial susceptibility test was carried out using basic microbiological procedures. Confirmation of all isolates was done using the VITEK 2 compact automated system (BioMerieux, Marcy l'Etoile France). The powdered dried seeds of $G$. kola were extracted with $70 \%$ methanol for 7 days, using a cold maceration method. The crude extracts were evaporated to dryness, using different solvents to obtain the fractions according to standard fractionation techniques. Results: The aqueous, butanol, chloroform and hexane fractions at minimum inhibitory concentrations (MIC) of $25 \mathrm{mg} / \mathrm{ml}$ were active against $A$. baumannii. Ethyl acetate fraction at MIC of $20 \mathrm{mg} / \mathrm{ml}$ also produced growth inhibition of same isolates. At the same MICs, the different fractions were observed to inhibit the growth of candida albicans (CF1) isolate. Overall, aqueous fraction of G. kola produced more growth inhibition followed by butanol fractions, with chloroform fractions producing the least effects. Conclusion: The antibacterial potencies of these extracts could be useful for the treatment of multi-drug-resistant $A$. baumannii. The aqueous fraction showed better activities than the other fractions studied.
\end{abstract}

Key words: Multidrug resistant bacteria, Clinical isolates, Garcinia kola, Minimum inhibitory concentration, Sensitivity.

\section{INTRODUCTION}

The use of herbal produce in the treatment of various ailments continue to receive worldwide attention by researchers as traditional medicines derived from plants have become highly important as alternative medicines in the treatment of a huge number of diseases. ${ }^{1-2}$ These plant derivatives are considered safe and more affordable for majority of the developing world. There are reports of an increase in the use of these plant produce in the developed world ${ }^{3}$ and more so with the emergence of difficult to treat bacterial infections, attention is again drawn to the use herbal alternatives. One of a long standing in use is the Garcinia kola.

Garcinia kola is commonly referred to in Nigeria as "Bitter kola" due to it characteristic bitter taste. The plant is grown in the humid regions of Western and Central Africa.-5 The tropical plant Garcinia belongs to the family Clusiaceae with origins said to be Asia, Australia, tropical and Southern Africa. ${ }^{6}$ The seeds of the plant, bitter kola, are used by some tribes in Nigeria for various ceremonial celebrations such as weddings, child naming ceremonies amongst others. At such celebrations, they are chewed as snacks ${ }^{7}$ and there is no specific amount that can be chewed at a sitting due to it friendliness to the digestive system. ${ }^{7}$ Chewing is believed to have a mechanical cleansing effect with the release of antimicrobial agents. ${ }^{8}$ Also, chewing of the seeds is reported to bring relief to coughs, colds and throat infections while earlier reports by $\mathrm{Iwu}^{9}$ stipulated that the plant derivatives are used in the treatment of liver disorders and jaundice. Thus, besides the chewing of Garcinia seeds for entertainment during celebrations, other parts of the plants such as the roots and the bark are used in herbal medicines. ${ }^{10}$ Generally, species of the family Garcinia have been used in the traditional treatments of various ailments such as dysentery, abdominal pains, and diarrhoea. ${ }^{11}$ The

Cite this article: Badger-Emeka LI, Khalil HE, Emeka PM. Evaluation of Different Fractions of Garcinia kola Extracts against Multidrug Resistant Clinical Bacterial and Fungal Isolates. Pharmacogn J. 2018;10(5):1055-60 
Table 1: Antimicrobial susceptibility of the gram negative bacterial clinical isolates used in the study

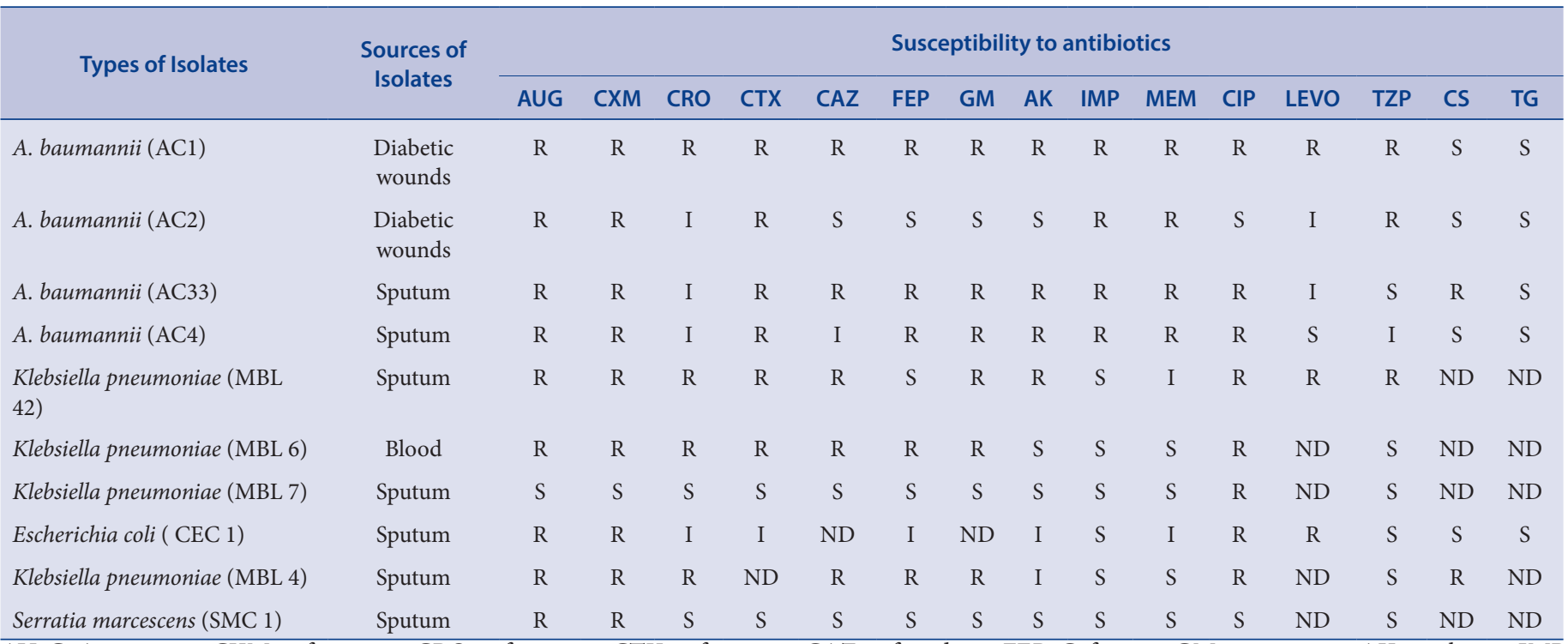

AUzG: Augmentin; CXM: cefuroxime; CRO: ceftriaxone; CTX: cefotaxime; CAZ: ceftazidime; FEP: Cefepime; GM: gentamicin; AK: amikacin; IMP: Imipenem; MEM: Meropenem; CIP: ciprofloxacin; LEVO: Levofloxacin; TZP: piperacillin-tazobactam; CS: Colistin; TG: Tigecycline; R/I; Resistant/ Intermediate. $\mathrm{R}=$ Resistant; $\mathrm{S}=$ Sensitive; $\mathrm{I}=$ Intermediate. ND: Not done

antibacterial biflavonoid of chewing Garcinia kola Kennel have also been isolated and characterised..$^{12}$ Also, the extracts of the Garcinia seeds are reported by Tchimene et al. ${ }^{13}$ and Ajayi et al. ${ }^{14}$ to have anti-inflammatory effects. These reports have therefore confirmed the reasons why the plant was named "wonder plant" due to its medicinal importance. ${ }^{4}$ Based on the antimicrobial properties of the Garcinia kola seed, Nwaokorie et al. ${ }^{10}$ reported the effect of the extracts on Fusobacterium nucleatum while the methanolic and aqueous extracts of the kola seeds were evaluated by Penduka et al. ${ }^{4}$ on Vibrio isolates and reported that both extracts inhibited the activities of the tested organisms. Other proven antimicrobial activities of the seed was earlier reported by various researches ${ }^{10,15-17}$ Most of the antimicrobial studies about G. kola extracts used different solvent extractions and reported different results. In addition, they used standard bacterial isolates that are sensitive to antibiotics. Therefore in the face of multidrug resistance being experienced clinically, the present study looks to investigate the antimicrobial activity of different extracted fractions of G. kola, on clinical gram negative multidrug resistant bacteria as well as Candida species.

\section{MATERIALS AND METHODS}

\section{Plant Material}

Garcinia kola seeds were used for this study and had been purchased from vendors in a local market in Lagos Nigeria.

\section{Preparation and fractionation of extract}

The seeds weighing $500 \mathrm{~g}$ were chopped into small portions, dried and grounded. The powdered seeds were exhaustively extracted three times with methanol for 7 days using $5.0 \mathrm{~L}$ of $70 \%$ methanol, at room temperature. The resulting solution was filtered using Whatman Grade1 filter paper, and evaporated to dryness with minimal pressure by the use of rotary evaporator. The residue gave a dark reddish-yellow compound weighing $40.0 \mathrm{~g}$ which was then suspended in double distilled water to obtain the aqueous fraction. Also successive extractions were done with hexane (3.0 1), chloroform (3.0 1), ethyl acetate (3.0 1), and butanol
(2.0 1). The different extracts were evaporated to dryness to yield hexane fraction (12.0 gm), chloroform fraction ( $5.0 \mathrm{gm})$, ethyl acetate fraction (4.0 gm), and butanol fraction (5.0 gm). The remaining aqueous mother liquor was dried to give the water-soluble fraction $(13.0 \mathrm{gm})$. Concentrations of $500 \mathrm{mg} / \mathrm{ml}$ was prepared from hexane fraction, chloroform fraction, butanol fraction and aqueous fraction. While $400 \mathrm{mg} / \mathrm{ml}$ was prepared from ethyl acetate fraction. Therefore, minimum inhibitory concentrations (MICs) were determined and found to be $25 \mathrm{mg} / \mathrm{ml}$ for hexane fraction, chloroform fraction, butanol fraction and aqueous fraction. MIC for ethyl acetate was $20 \mathrm{mg} / \mathrm{ml}$.

\section{Clinical Isolates}

The following clinical Gram negative bacterial and fungal isolates were used for the investigation: Klebsiella pneumoniae, Escherichia coli, Acinetobacter baumannii, Enterobacter species, Serratia marcescens, Candida albicans isolates CF1, CF2, and CF3. They were obtained from the medical microbiology laboratory of the college of medicine at King Faisal University. Isolates had been obtained from clinical samples of blood, sputum diabetic and non-diabetic wounds.

\section{Microbial culture and antibiotic susceptibility testing.}

Bacterial isolates were grown on MacConkey agar incubated at $37^{\circ} \mathrm{C}$ for $24 \mathrm{~h}$. Pure colonies of the isolates were used for the identification and antimicrobial susceptibility testing. Confirmation of the identified isolates was carried out using BioMerieux VITEK 2 compact automated system (BioMerieux, Marcy I'Etoile France), according to the manufacturers guidelines. The antimicrobial susceptibility testing was also carried out using the GN (Gram negative) cards of the BioMerieux VITEK 2 compact automated system (BioMerieux, Marcy I'Etoile France) according to the manufacturer's guidelines. The GN cards consisted of the following antibiotics: Augmentin, ceftriaxone, cefotaxime, ceftazidime, Cefepime, gentamicin, amikacin, Imipenem, Meropenem, Ciprofloxacin, Levofloxacin, piperacillin-Tazobactam, Colistin, Tigecycline and tetracycline. 
Badger-Emeka, et al.: Antimicrobial activity of Fractions of Garcinia kola on MDR agents

Table 2: Showing extent of growth inhibition of clinical microbial isolates by various extracted fractions of Garcinia kola.

\begin{tabular}{|c|c|c|c|c|c|c|c|}
\hline \multirow[t]{2}{*}{ Types of Isolates } & \multirow[t]{2}{*}{ Sources of Isolates } & \multicolumn{6}{|c|}{ Different fractions of Garcinia kola } \\
\hline & & DMSO & CF & BF & EF & HF & AQF \\
\hline A. baumannii (AC1) & Diabetic wounds & $0.6 \mathrm{~mm}$ & $14 \mathrm{~mm}$ & $14 \mathrm{~mm}$ & $11 \mathrm{~mm}$ & $11 \mathrm{~mm}$ & $16 \mathrm{~mm}$ \\
\hline A. baumannii (AC2) & Diabetic wounds & $10 \mathrm{~mm}$ & $15 \mathrm{~mm}$ & $16 \mathrm{~mm}$ & $18 \mathrm{~mm}$ & $14 \mathrm{~mm}$ & $17 \mathrm{~mm}$ \\
\hline A. baumannii (AC33) & Sputum & $10 \mathrm{~mm}$ & $10 \mathrm{~mm}$ & $12 \mathrm{~mm}$ & $16 \mathrm{~mm}$ & $16 \mathrm{~mm}$ & $18 \mathrm{~mm}$ \\
\hline A. baumannii (AC4) & Sputum & $10 \mathrm{~mm}$ & $10 \mathrm{~mm}$ & $12 \mathrm{~mm}$ & $10 \mathrm{~mm}$ & $10 \mathrm{~mm}$ & $14 \mathrm{~mm}$ \\
\hline Klebsiella pneumoniae (MBL 42) & Sputum & $10 \mathrm{~mm}$ & $10 \mathrm{~mm}$ & $10 \mathrm{~mm}$ & $10 \mathrm{~mm}$ & $10 \mathrm{~mm}$ & $10 \mathrm{~mm}$ \\
\hline Klebsiella pneumoniae (MBL 6) & Blood & $10 \mathrm{~mm}$ & $10 \mathrm{~mm}$ & $10 \mathrm{~mm}$ & $10 \mathrm{~mm}$ & $10 \mathrm{~mm}$ & $10 \mathrm{~mm}$ \\
\hline Klebsiella pneumoniae (MBL 7) & Sputum & $10 \mathrm{~mm}$ & $10 \mathrm{~mm}$ & $10 \mathrm{~mm}$ & $10 \mathrm{~mm}$ & $11 \mathrm{~mm}$ & $15 \mathrm{~mm}$ \\
\hline Escherichia coli ( CEC 1) & Sputum & $10 \mathrm{~mm}$ & $10 \mathrm{~mm}$ & $10 \mathrm{~mm}$ & $10 \mathrm{~mm}$ & $10 \mathrm{~mm}$ & $10 \mathrm{~mm}$ \\
\hline Klebsiella pneumoniae (MBL 4) & Sputum & $10 \mathrm{~mm}$ & $10 \mathrm{~mm}$ & $10 \mathrm{~mm}$ & $10 \mathrm{~mm}$ & $10 \mathrm{~mm}$ & $10 \mathrm{~mm}$ \\
\hline Serratia marcescens (SMC 1) & Sputum & $10 \mathrm{~mm}$ & $10 \mathrm{~mm}$ & $10 \mathrm{~mm}$ & $10 \mathrm{~mm}$ & $10 \mathrm{~mm}$ & $10 \mathrm{~mm}$ \\
\hline Candida albicans (CFI 1) & Sputum & $0 \mathrm{~mm}$ & $12 \mathrm{~mm}$ & $10 \mathrm{~mm}$ & $12 \mathrm{~mm}$ & $13 \mathrm{~mm}$ & $12 \mathrm{~mm}$ \\
\hline Candida albicans (CFI 2) & Sputum & $10 \mathrm{~mm}$ & $10 \mathrm{~mm}$ & $10 \mathrm{~mm}$ & $10 \mathrm{~mm}$ & $10 \mathrm{~mm}$ & $10 \mathrm{~mm}$ \\
\hline Candida albicans (CFI 3) & Sputum & $10 \mathrm{~mm}$ & $10 \mathrm{~mm}$ & $10 \mathrm{~mm}$ & $10 \mathrm{~mm}$ & $10 \mathrm{~mm}$ & $10 \mathrm{~mm}$ \\
\hline
\end{tabular}

DMSO: Dimethyl sulfoxide; CF: Chloroform Fraction; BF: Butanol Fraction; ethyl acetate Fraction; HF: hexane Fraction; AQF: Aqueous fraction

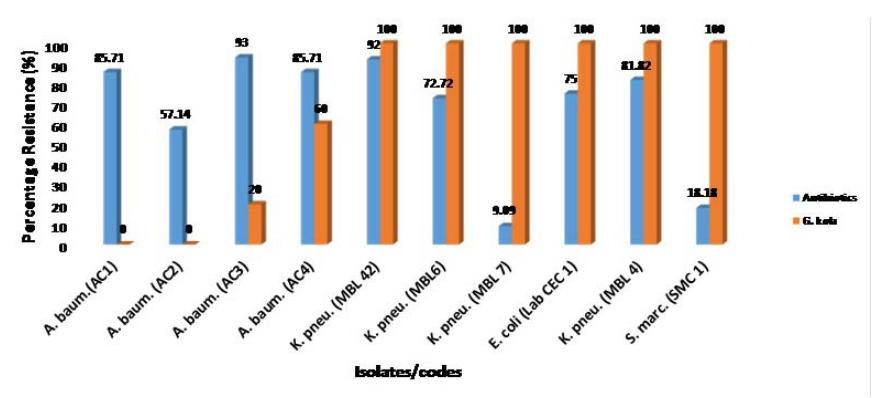

Figure 1: A comparison between percentage resistance to antimicrobials and Garcinia kola fractions.

\section{Determination of Minimum inhibitory concentrations (MIC)}

The MICs of the various fractions of Garcinia Kola ((Heckel) seed extracts were determined by the broth dilution method, according to the method described by Asowata et al. ${ }^{18}$ All the fractions were prepared to the highest concentration of $500 \mathrm{mg} \mathrm{ml}$ (stock concentration) in sterile distilled water, which were then serially diluted to give concentrations ranging from $40 \mathrm{mg} / \mathrm{ml}$ to $10 \mathrm{mg} \mathrm{ml} .1 \mathrm{ml}$ of the standardized microbial broth cultures were inoculated into the tubes containing the diluted extracts and labelled accordingly. The tubes were incubated at $37^{\circ} \mathrm{C}$ temperature for $24 \mathrm{~h}$ for the clinical bacteria isolates and for $48 \mathrm{~h}$ for fungi. They were examined for the presence or absence of bacterial or fungal growth. The least concentration of the extract which inhibited the growth of the inoculums was considered as the minimum inhibitory concentration.

\section{RESULTS}

The results in Table 1 shows the antimicrobial susceptibility of bacteria isolates used in this study. The least resistance to antimicrobials were Klebsiella pneumonia (MBL 7) and Serratia marcescens (SMC1) with 9. 09 and 18.18 percentage resistance respectively. Both bacterial isolates were from sputum specimens. The antimicrobial resistance pattern for Acinetobacter isolates $\mathrm{AC} 1, \mathrm{AC} 2, \mathrm{AC} 3$ and $\mathrm{AC} 4$ were $85.71 \%, 57.14 \%$, and 93\%, respectively. For the Klebsiella pneumoniae MBL42, MBL 6, and MBL 4, percentage antimicrobial resistance was $92 \%, 72.72 \%$ and $81.82 \%$ respectively. These isolates were resistant to at least 3 classes of antibiotic groups and therefore termed multidrug resistant organisms. Out of all the isolates used two were resistant to colistin antibiotics, a drug regarded as the last resort to the treatment of multidrug resistant bacteria. The table also describes different sources of isolates, showing that most of the isolates were from sputum, with only one was from blood sample while A. baumannii, AC1 and AC1 were isolated from diabetic wounds. All the fungal isolates had been from sputum (Table 2). Comparing the susceptibility pattern of diabetic wound isolates with those collected from sputum, in terms of resistance, no main differences were observed. The extent of growth inhibition of the clinical isolates by different fractions of G. kola is described in Table 2. It showed that all the A. baumannii isolates from either diabetic or sputum samples were susceptible to aqueous fraction followed by the butanol fraction, then ethyl acetate fraction and hexane fraction. The chloroform fraction is the least active compared to all the extracted fractions. However, isolates MBL42, MBL6, MBL7, CEC1, MBL4 and SMC1 were however, resistant to all the extracted fractions of $G$. kola. The table also shows the susceptibility of three different clinical strains of Candida albicans isolates to the various fractions. Of the three, only one (CF1) showed sensitivity to all the fractions, the rest were resistant. Table 3 , shows the comparison of antibiotics group with different fractions of G. kola. The results records that aqueous and butanol fractions appeared to have the highest sensitivity on all the A. baumannii multidrug resistant isolates. Their effect on these isolates were similar to the effect produced by tigecycline. One of the isolates (AC3) that was resistant to colistin exhibited sensitivity to both aqueous and butanol fractions of G. kola. The effect of ethyl acetate and hexane fractions were more than that of chloroform fraction. However, all the isolates were resistant to beta lactams, aminoglycosides and fluoroquinolones. Table 4 describes the MICs as obtained from Vitek 2. The MICs for antibiotics against clinical isolates from diabetic wounds, sputum and blood ranged from $0.5-64 \mu \mathrm{g} / \mathrm{ml}$ for both sensitive and resistant isolates. MICs determined for G. kola for this study ranged from $20-25 \mathrm{mg} / \mathrm{ml}$. However, these fractions are still in their crude form and therefore not pure compounds. A comparison between percentage resistance to antimicrobials and fractions of G. kola is shown in Figure 1. The least resis- 
Badger-Emeka, et al.: Antimicrobial activity of Fractions of Garcinia kola on MDR agents

Table 3: Showing sensitivity of multi-drug resistant clinical isolates of A. baumannii to fractions Garcinia kola

\begin{tabular}{llllllllllllll}
\hline \multirow{2}{*}{ Types of Isolates } & \multirow{2}{*}{$\begin{array}{l}\text { Sources of } \\
\text { Isolates }\end{array}$} & CF & BF & EF & HF & AQF & BLTM & AMG & FQN & CABP & TIG & COL \\
\hline & D. baumannii (AC1) & Diabetic wounds & S & S & S & S & S & R & R & R & R & S & S \\
A. baumannii (AC2) & Diabetic wounds & S & S & S & S & S & R & S & R & R & S & S \\
A. baumannii (AC3) & Sputum & R & S & S & S & S & R & R & R & R & S & R \\
A. baumannii (AC4) & Sputum & R & S & R & R & S & R & R & R & R & S & S \\
\hline
\end{tabular}

CF: Chloroform Fraction; BF: Butanol Fraction; ethyl acetate Fraction; HF: hexane Fraction; AQF: Aqueous fraction BLTM:

Beta-lactam agents; AMG: Aminoglycosides; FQN: Fluoroquinolones; CABP: Carbapenems; TIG: Tigecycline; COL: Colistin

Table 4: Antimicrobial MICs Determined by Vitek 2.

\begin{tabular}{|c|c|c|c|c|c|c|c|c|c|c|c|c|c|c|c|c|}
\hline \multirow{2}{*}{ Types of Isolates } & \multirow{2}{*}{$\begin{array}{l}\text { Sources of } \\
\text { Isolates }\end{array}$} & \multicolumn{15}{|c|}{ MICs antibiotics $(\mu \mathrm{g} / \mathrm{ml})$} \\
\hline & & AUG & CXM & CRO & CTX & CAZ & FEP & GM & AK & IMP & MEM & CIP & LEVO & TZP & CS & TG \\
\hline A. baumannii (AC1) & $\begin{array}{l}\text { Diabetic } \\
\text { wounds }\end{array}$ & $\geq 32$ & $\geq 64$ & $\geq 64$ & $\geq 64$ & $\geq 32$ & $\geq 32$ & $\geq 16$ & $\geq 64$ & $\geq 16$ & $\geq 16$ & $\geq 4$ & $\geq 8$ & $\geq 16$ & $\geq 2$ & $\geq 0.5$ \\
\hline A. baumannii (AC2) & $\begin{array}{l}\text { Diabetic } \\
\text { wounds }\end{array}$ & $\geq 32$ & $\geq 64$ & $\geq 32$ & $\geq 64$ & $\geq 8$ & $\geq 8$ & $\geq 4$ & $\geq 16$ & $\geq 16$ & $\geq 16$ & $\begin{array}{l}\geq \\
0.25\end{array}$ & $\geq 8$ & $\geq 16$ & $\geq 2$ & $\geq 0.5$ \\
\hline A. baumannii (AC33) & Sputum & $\geq 32$ & $\geq 64$ & $\geq 32$ & $\geq 64$ & $\geq 32$ & $\geq 32$ & $\geq 16$ & $\geq 64$ & $\geq 16$ & $\geq 16$ & $\geq 4$ & $\geq 8$ & $\geq 4$ & $\geq 4$ & $\geq 0.5$ \\
\hline A. baumannii (AC4) & Sputum & $\geq 32$ & $\geq 64$ & $\geq 32$ & $\geq 64$ & $\geq 16$ & $\geq 32$ & $\geq 16$ & $\geq 64$ & $\geq 16$ & $\geq 16$ & $\geq 4$ & $\geq 4$ & $\geq 8$ & $\geq 2$ & $\geq 0.5$ \\
\hline $\begin{array}{l}\text { Klebsiella pneumoniae } \\
\text { (MBL 42) }\end{array}$ & Sputum & $\geq 32$ & $\geq 64$ & $\geq 64$ & $\geq 64$ & $\geq 32$ & $\geq 8$ & $\geq 16$ & $\geq 64$ & $\geq 4$ & $\geq 8$ & $\geq 4$ & $\geq 2$ & $\geq 16$ & ND & $\mathrm{ND}$ \\
\hline $\begin{array}{l}\text { Klebsiella pneumoniae } \\
\text { (MBL 6) }\end{array}$ & Blood & $\geq 32$ & $\geq 64$ & $\geq 64$ & $\geq 64$ & $\geq 32$ & $\geq 32$ & $\geq 16$ & $\geq 16$ & $\geq 4$ & $\geq 4$ & $\geq 4$ & ND & $\geq 4$ & ND & ND \\
\hline $\begin{array}{l}\text { Klebsiella pneumoniae } \\
\text { (MBL 7) }\end{array}$ & Sputum & $\geq 8$ & $\geq 8$ & $\geq 8$ & $\geq 32$ & $\geq 8$ & $\geq 8$ & $\geq 4$ & $\geq 16$ & $\geq 4$ & $\geq 4$ & $\geq 4$ & ND & $\geq 4$ & ND & $\mathrm{ND}$ \\
\hline Escherichia coli (CEC 1) & Sputum & $\geq 32$ & $\geq 64$ & $\geq 32$ & $\geq 32$ & ND & $\geq 16$ & ND & $\geq 32$ & $\geq 4$ & $\geq 8$ & $\geq 8$ & $\geq 8$ & $\geq 4$ & $\geq 2$ & $\geq 0.5$ \\
\hline $\begin{array}{l}\text { Klebsiella pneumoniae } \\
\text { (MBL 4) }\end{array}$ & Sputum & $\geq 32$ & $\geq 64$ & $\geq 64$ & ND & $\geq 32$ & $\geq 32$ & $\geq 16$ & $\geq 32$ & $\geq 16$ & $\geq 4$ & $\geq 4$ & ND & $\geq 4$ & $\geq 4$ & ND \\
\hline $\begin{array}{l}\text { Serratia marcescens } \\
\text { (SMC 1) }\end{array}$ & Sputum & $\geq 32$ & $\geq 64$ & $\geq 8$ & $\geq 8$ & $\geq 8$ & $\geq 8$ & $\geq 4$ & $\geq 16$ & $\geq 4$ & $\geq 4$ & $\geq 4$ & ND & $\geq 4$ & ND & ND \\
\hline
\end{tabular}

AUG: Augmentin; CXM: cefuroxime; CRO: ceftriaxone; CTX: cefotaxime; CAZ: ceftazidime; FEP: Cefepime; GM: gentamicin; AK: amikacin; IMP: Imipenem; MEM: Meropenem; CIP: ciprofloxacin; LEVO: Levofloxacin; TZP: piperacillin-tazobactam; CS: Colistin; TG: Tigecycline; R/I; Resistant/ Intermediate. $\mathrm{R}=$ Resistant; $\mathrm{S}=$ Sensitive; $\mathrm{I}=$ Intermediate.

tant to antibiotic isolates MBL7 and SMC 1 were highly resistant to the G. kola fraction.

\section{DISCUSSION}

The present study showed that $G$. kola extracts have antimicrobial activity against multi-drug resistance clinical isolates, A. baumannii. The aqueous fraction of $G$. kola seeds exhibited a better antimicrobial activity as compared to the other fractions. These effects were similar to the results obtained from other studies conducted using antimicrobial sensitive bacteria isolates. ${ }^{19}$ Our observations also corroborates the findings of Ezeigbo et al. ${ }^{20}$ who reported growth inhibition with aqueous extracts on gram negative sensitive bacteria. However, a number of studies documented a contrary view, observing that their aqueous extract had little or no antibacterial activity. ${ }^{21-23}$ Thus pointing to the fact that reports of the antimicrobial effects of $G$. kola varies between available reports. Interestingly, in the present investigation, a strain of A. baumannii (AC3) clinical isolate that was resistant to colistin, a last line antibiotic, was sensitive to this fraction of G. kola. It was also found to be active against a strain of Candida albicans clinical isolate (CFI 1), an observation that was similar to the work of Penduka and Okoh. ${ }^{22}$ The butanol fraction of the extract was found to be active against all the A. baumannii isolates and candida albicans (CFI 1). According to Akinpelu et al. ${ }^{16}$ butanol extract of G. kola, exhibited antibacterial activity against Bacillus anthracis and E. coli sensi- tive isolates. Thus, with the antifungal effects as seen in this investigation, butanol fraction of $G$. kola can be said to be exhibiting broad spectrum activity. Regarding the chloroform fraction of the extract, we observed that it was not as active on bacterial growth inhibition as compared to the other fractions. This finding is in line with the study of Akinpelu et al. ${ }^{16}$ whose investigation with chloroform extract produced no antibacterial activity on sensitive isolates tested. The reason could be that as reported by Morabandza et al..$^{24}$ chloroform fractions of $G$. kola contains less flavonoids compared to other fractions. This may account for the reason why it has less antibacterial activity compared to other fractions. The present study also observed that the hexane fraction produced a significant activity against three multidrug resistant clinical isolates of $A$. baumannii and C. albicans (CFI 1) and can therefore be described as having antimicrobial activities. Similar findings had been reported by other workers who found that hexane fraction of G. kola, had appreciable anti-listeria activity. ${ }^{24}$ Crude ethyl acetate fraction showed antibacterial activity also like the hexane fraction. Our observation concerning its antibacterial effects was also documented ${ }^{16}$ by researchers, in which they reported significant activity against both gram positive and gram negative bacteria. The said antibacterial activity by them, ${ }^{16}$ was observed on $K$. pneumoniae and E. coli at a much lower minimum inhibitory concentration. However, the isolates used in their study were standard laboratory bacterial isolates and not multidrug resistant isolates as those used 
Badger-Emeka, et al.: Antimicrobial activity of Fractions of Garcinia kola on MDR agents

in the present study. It is worth noting the diversity in bacteria strains such as those of Escherichia coli from those that are pathogenic to the non-pathogenic. In the present investigation, we report that none of the fractions extracts were able to inhibit the growth of multidrug resistant E. coli and K. pneumoniae isolated from clinical source, sputum. The findings could be attributed to the diversity in bacterial stains in as well as their ability to be antibiotic sensitive, MDR or not resistant to antibiotics. The present study also observed that all the fractions appeared to exhibit more activity on diabetic wound isolates than sputum isolates, particularly A. baumannii. The observation that MDR clinical isolate $A$. baumannii AC3 was sensitive to majority of the fractions of Garcinia kola extract was particularly interesting. This is because, this isolate was resistant to colistin antibiotic, a last line drug usually reserved for treatment of recalcitrant bacteria organisms. The minimum inhibitory concentrations employed in the present study compared to previous studies ranged from $20-25 \mathrm{mg} / \mathrm{ml}$. A number of studies reported MIC range of 5-20mg/ $\mathrm{ml}$ with $20 \mathrm{mg} / \mathrm{ml}$ MIC showing greater growth inhibition. ${ }^{16,25-26}$ Therefore, the variation in MICs seen with different studies and also different antibacterial activities reported from extracted fractions could be due to methods and solvent used in the various extractions procedure. Other workers like Penduka and $\mathrm{Okoh}^{22}$ reported MIC of $10 \mathrm{mg} / \mathrm{ml}$. Therefore, it is important to harmonise the extraction procedure so as to see a consistent and reproducible results that will serve as a reference. However, for multidrug resistant isolates, a higher MICs will be expected. MICs for antibiotics employed for resistant organisms are usually higher. All the previous studies referred to in this presented study, reported lower antibiotics as positive controls. This is because, their isolates were not multidrug resistant organisms. The range of antibiotics used in this present study was from $464 \mu \mathrm{g} / \mathrm{ml}$ according to the estimation of the Vitek 2 for the tested multidrug resistant isolates. The consequences of multidrug resistant bacteria infection is far reaching. Finding an alternative therapy that is cheap and non-toxic is crucial but urgent. Because of the availability of herbal plants and safety of their use, coupled with proven efficacy, a lot of interest and attention are focused on them. Garcinia kola products has been shown to be potential medicaments to be used in the treatments of many diseases and scientists have taken interest. ${ }^{20,23}$ The present study therefore shows that aqueous fraction of Garcinia seeds possesses the potential to be used as antimicrobial agent.

\section{CONCLUSION}

Since the effectiveness of current antimicrobial agents are decreasing due to bacterial resistance and treatment failures are experienced by clinicians, the results obtained from this study could provide leads to be further investigated for the development of potential antimicrobial agents of natural origin. G. kola extracts have further shown that they could be useful as potential antibacterial agents.

The researchers would like to thank Dr. Kazeem Yusuf for the provision of the Garcinia kola seeds bought from Nigeria.

\section{CONFLICT OF INTEREST}

The authors declare no conflict of interest.

\section{ABBREVIATIONS}

MDR - Multidrug resistant; MIC - Minimum inhibitory concentration; AC1 - Acinetobacter Clinical isolate 1; AC2 - Acinetobacter Clinical isolate 2; AC3 - Acinetobacter Clinical isolate 3; AC4 - Acinetobacter Clinical isolate 4; MBL 42 - Microbiology lab 42; MBL 4 - Microbiology lab 42; MBL 6 - Microbiology lab 42; MBL 7 - Microbiology lab 42; CEC 1 - Clinical Escherichia coli 1; SMC 1 - Serratia marcescens Clinical isolate
1CF1 - Clinical fungi isolate 1; CF2 - Clinical fungi isolate 2; CF3 - Clinical fungi isolate 3 .

\section{REFERENCES}

1. Emeka PM, Badger-Emeka LI, Fateru F. In vitro antimicrobial activities of Acalypha ornate leaf extracts on bacterial and fungal clinical isolates. Journal of Herbal Medicine. 2012;2(4):136-42.

2. Sofowora A. Medicinal plants and traditional medicine in Africa. $3^{\text {rd }}$ ed. Ibadan: Spectrum Books Limited. 2008:179-93.

3. Parekh J, Jadeja D, Chanda S. Efficacy of aqueous and methanol extract of some medicinal plants for potential antibacterial activity. Turk J Biol Sci. 2005;29(4):203-10.

4. Penduka D Okoh OO Okoh Al. In-vitroAntagonistic Characteristics of Crude Aqueous and Methanolic Extracts ofGarcinia kola(Heckel) Seeds against Some Vibrio Bacteria. Molecules. 2011;16(4):2754-65. http://doi:10.3390/molecules 16042754.

5. Adefule AO, Adefule AK, Oosa BO, Onyenefa PC. Antifungal activity of Garcinia kola nut extract as an ocular bacterial isolates in Lagos. Nig Q J Hosp Med. 2004; 14:112-4.

6. Seruji NMU, Khong HY, Kutoi CJ. Antioxidant, anti-inflammatory and Cytotoxic activities of Garcinia nervosa (Clusiaceae). Hindawi publishing cooperation. J Chem. 2013;11:1-5. http://dx.doi.org/10.1155/2013/913406

7. Adebisi AA. A case study of Garcinia kola nut production-to consumption system in J4 Area of Omo forest reserve, Southwest Nigeria. In: Sunderland T, Ndoye O. (eds). Forest products, livelihoods and conservation: case studies on non-timber forest systems. Bogor Barat: Center for International Forstry Research. 2004;115-32.

8. Han YW, Ikegami A, Rajanna C, Kawsar H, Zhou Y, Li M, et al. Identification and characterization of novel adhesin unique to oral Fusobacteria. J Bacteriol. 2005;187(15):5330-40.

9. Iwu MM. Handbook of African Medicinal Plants; CRC Press: Boca Raton, FL, USA, 1993;183-4.

10. Nwaokorie F, Coker A, Ogunsola F, Gaetti-Jardim JE, Gabriel O, Ayanbadejo P, et al. Antimicrobial activities of Garcinia kola on oral Fusobacterium nucleatum and biofilm. African Journal of Microbiology Research. 2010;4(7):509-14. Available online http://www.academicjournals.org/ajmr.

11. Jayaprakasha GK, Negi PS, Jena BS. Antioxidative and antimutagenic activities of the extracts from the rinds of Garcinia pedunculata. Innovative Food Science and Emerging Technologies. 2006;7(3):246-50.

12. Xu HX,Mughal S, Taiwo O, Lee SF. Isolation and characterization of an antibacterial biflavonoid from an African chewing stick Garcinia kola Heckel (Clusiaceae). Ethnopharmacol. 2013;147(2):497-502. doi: 10.1016/j.jep.2013.03.047.

13. Tchimene KM, Anaga AO, Ugwoke CEC, Ezugwu CO, Okunji C, Iwu MM. Bioflavonoids and Garcinoic Acid from Garcinia kola seeds with Promising AntiInflammatory Potentials. Pharmacognosy Journal. 2016;8(1):56-8.

14. Ajayi SA, Ofusori DA, Ojo GB, Ayoka OA, Abayomi TA, Tijani AA. The microstructural effects of aqueous extract of Garcinia kola (Linn) on the hippocampus and cerebellum of malnourished mice. Asian Pac J Trop Biomed. 2011;1(4):261-5. http://doi:10.1016/S2221-1691(11)60039-7.

15. Sibanda T, Okoh Al. In-vitro antibacterial regimes of crude aqueous and acetone extracts of Garcinia kola seeds. J Biol Sci. 2008;8(1):149-54.

16. Akinpelu DA, Adegboye MF, Adeloye OA, Okoh Al. Biocidal activity of partially purified fractions from methanolic extract of Garcinia kola (Heckel) seeds on bacterial isolates. Biol Res. 2008;41(3):277-87.

17. Ezeifeka GO, Orji MU, Mbata TI, Patrick AO. Antimicrobial activities of Cajanus cajan, Garcinia kola and Xylopia aethiopica on pathogenic microorganisms. Biotechnology. 2004;3(1):41-3.

18. Asowata I, Erhabor JO, Idu M, Odaro T, Obayagbona NO. Preliminary antimicrobial and phytochemical study of the aqueous, alcoholic and chloroform extracts of the leaves of Napoleonaea vogelli Hook and Planch. (Lecythidiaceae). J Microbiol Biotechnol Food Sci. 2013;2(4):2279-92.

19. Njume C, Jide AA, Ndip RN. Aqueous and Organic Solvent-Extracts of Selected South African Medicinal Plants Possess Antimicrobial Activity against DrugResistant Strains of Helicobacter pylori: Inhibitory and Bactericidal Potential. International Journal of Molecular Sciences. 2011;12(9):5652-65. doi:10.3390/ ijms12095652.

20. Ezeigbo OR, Ejike EN, Nwachukwu I, Ejike BU. Comparative Antibacterial Activity of Methanolic, Ethanolic and Aqueous Extract of Garcinia kola (Bitter kola) and Cola nitida (Kola nut). International Journal of Plant Research. 2016;6(3):536. doi: 10.5923/j.plant.20160603.01.

21. Sibanda T, Olaniran AO, Okoh Al. In-vitro antibacterial activities of crude extracts of Garcinia kolaseeds against wound sepsis associated Staphylococcus strains. J Med Plants Res. 2010;4:710-6.

22. Penduka D, Okoh Al. In vitro Anti-Listerial Activities of Crude n-Hexane and Aqueous Extracts of Garcinia kola (heckel) Seeds. International Journal of Molecular Sciences. 2011;12(10):6952-65. doi:10.3390/ijms12106952.

23. Seanego CT, Ndip RN. Identification and Antibacterial Evaluation of Bioactive Compounds from Garcinia kola (Heckel) Seeds. Molecules. 2012;17(6):6569-84. 
24. Morabandza CJ, Ongoka RP, Matini L, Epa C, Nkounkou LC, Abena AA. Chemical Composition of the Mesocarp of Garcinia kola Heckel (Clusiaceae) Fruit. Research Journal of Recent Sciences. 2013;2(1):53-8.

25. Adeleke OE, Coker ME, Oke OB. Detection of a Gentamicin-Resistant Burn Wound Strain of Pseudomonas Aeruginosa but Sensitive to Honey and Garcinia Kola (Heckel) Seed Extract. Annals of Burns and Fire Disasters. 2010;23(2):102-
26. Akinnibosun $\mathrm{Fl}$, Itedjere E. Evaluation of the antibacterial properties and synergistic effect of Garcinia kola Heckel (Family: Guttiferae) seed extract and honey on some bacteria. African Journal of Microbiology Research. 2013;7(3):174-80. DOI: $10.5897 / A J M R 12.1331$.

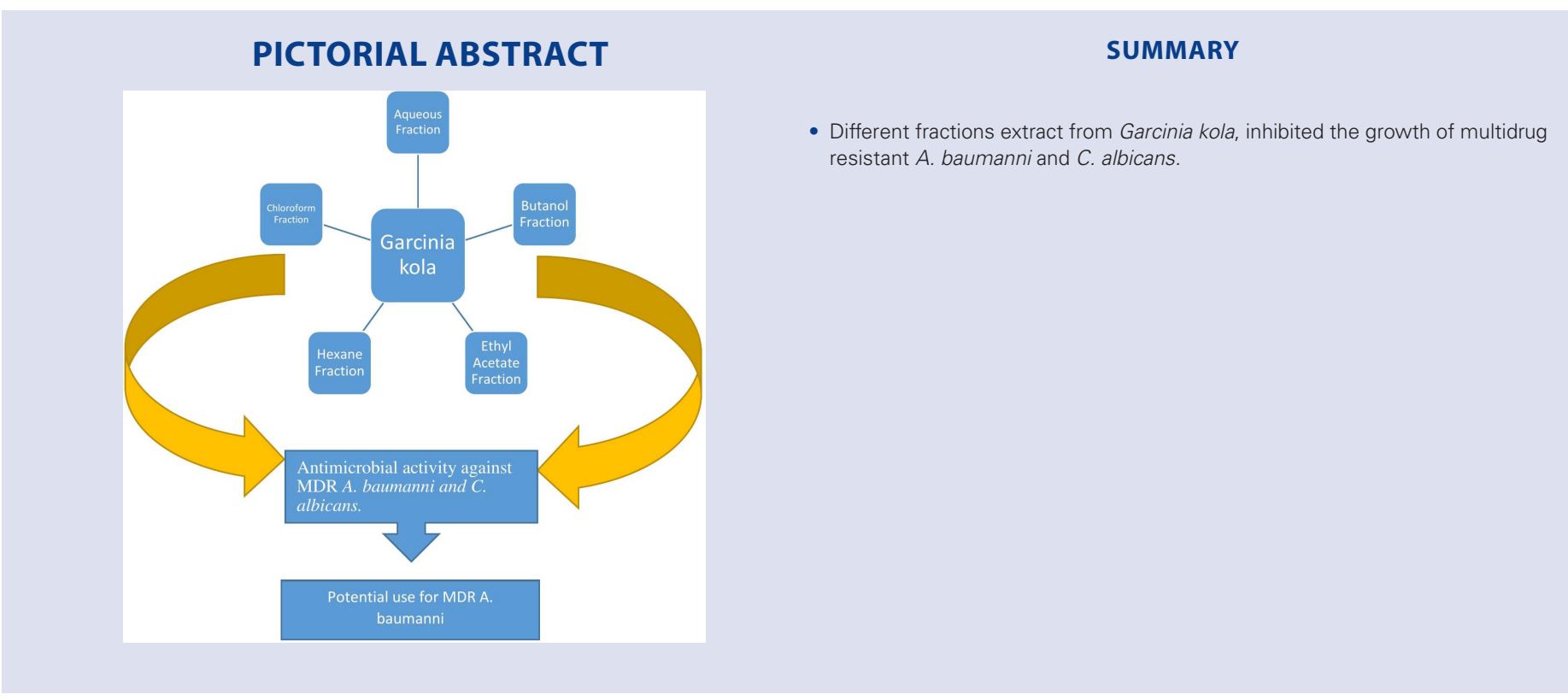

Cite this article: Badger-Emeka LI, Khalil HE, Emeka PM. Evaluation of Different Fractions of Garcinia kola Extracts against Multidrug Resistant Clinical Bacterial and Fungal Isolates. Pharmacogn J. 2018;10(5):1055-60 